\title{
DESCRIÇÃO FONÉTICO-ACÚSTICA DOS RÓTICOS EM TRAVAMENTO DE SÍLABA TÔNICA NA FALA DE CURITIBANOS: UM ESTUDO COMPARATIVO DE DUAS GERAÇÕES
}

AN ACOUSTIC ANALYSIS OF RHOTICS IN CODA POSITION IN SPEECH SAMPLES OF INFORMANTS FROM CURITIBA: A CROSS GENERATIONAL COMPARATIVE STUDY

\section{Thaís Deschamps}

Mestranda do Programa de Pós-graduação em

Letras da UFPR

thadeschamps@gmail.com

\author{
Kayron Beviláqua \\ Mestrando do Programa de Pós-graduação \\ em Letras da UFPR \\ kayronbevilacqua@hotmail.com
}

RESUMO: O objetivo deste trabalho é caracterizar acusticamente as produções de róticos em coda silábica em amostras de fala de informantes curitibanos. Nossa hipótese era que a variante retroflexa estivesse em disseminação em Curitiba, e realizamos um experimentopiloto com falantes de duas gerações para verificar se havia diferença geracional. Os dados apontaram, entretanto, que não houve mudança entre as gerações, o que levanta a hipótese de este som já estar presente no dialeto curitibano há mais tempo do que se supunha.

PALAVRAS-CHAVE: Fonética acústica. Róticos. Curitiba.

ABSTRACT: The aim of this paper is to investigate, by acoustic analysis, the production of rhotics in coda position in the Curitiba dialect. Our hypothesis is that the retroflex was spreading in Curitiba, and we conducted a pilot experiment with speakers of two different generations to verify if there were generational differences. The data showed, however, that there was no change between generations, which raises the question of whether the retroflex approximant is part of this dialect for longer than previously thought.

KEYWORDS: Acoustic Phonetics. Rhotics. Curitiba.

\section{INTRODUÇÃO}

A classe dos róticos suscita há tempos o interesse de pesquisadores em Fonética e Fonologia devido ao seu caráter ambivalente: enquanto essa classe parece ter existência fonológica (cf. Lindau, 1985; Silva, 1996), é bastante difícil encontrar correlatos fonéticos, articulatórios ou 
acústicos, que permitam efetivamente agrupar seus elementos de acordo com alguma propriedade que todos compartilhem. De fato, como apontado por Lindau (1985), os róticos parecem estar relacionados entre si em uma grande família (dentro da qual há relações de maior proximidade entre alguns de seus elementos), mas não é possível encontrar uma correspondência de um-a-um entre suas propriedades fonéticas e fonológicas.

$\mathrm{Na}$ busca por entender um pouco mais a classe dos róticos no português brasileiro (doravante $\mathrm{PB}$ ), escolheu-se como objeto de estudo deste trabalho a realização dos sons de /r/ em coda silábica na fala de curitibanos. A descrição acústica da realização dos róticos para esse dialeto se justifica por ainda haver poucos estudos acústicos para esses sons nesse dialeto. Deve-se mencionar, nesse sentido, o trabalho de Clemente (2009) sobre a alofonia gradiente dos róticos em posição de coda final na fala de Curitiba. Na esteira de Clemente (2009), este estudo busca verificar em que medida seus resultados podem ser estendidos para coda silábica não-final (i.e. medial). Nosso interesse especial pela posição final de sílabas reside no fato de que é nela que temos maiores chances de encontrar a variante retroflexa. Essa variante é encontrada nas mais diversas regiões do país, sendo marca principal do chamado "dialeto caipira” paulista (mas já se espalhou pelo estado de São Paulo para além das regiões interioranas). No estado paranaense, essa variante parece estar em franca disseminação, principalmente em posição de coda silábica, como mostram os trabalhos de Ferraz (2005) e o já citado de Clemente (2009). Dessa forma, para conseguirmos capturar realizações do retroflexo, parece necessário privilegiar produções de róticos em posição de coda silábica, portanto. Um estudo mais amplo sobre os róticos que contemple posições iniciais e entre vogais, no entanto, seria interessante e necessário para que pudéssemos ter uma descrição geral da realização dessa classe no dialeto curitibano.

Este trabalho visa a contribuir, portanto, para a caracterização fonético-acústica dos róticos do PB (especialmente, do retroflexo) e, através de um estudo-piloto, observar se há uma tendência de disseminação do retroflexo na fala de jovens curitibanos, em relação à fala de gerações anteriores. Nossa hipótese inicial, baseados em Clemente (2009), é que a variante retroflexa dos róticos já tenha chegado ao dialeto curitibano, ao menos na posição de coda silábica. Neste sentido, espera-se encontrar essa variante com maior frequência na fala dos jovens do que na fala da geração mais velha. Estabelecem-se, portanto, como objetivos específicos:

i. Descrever como os róticos se realizam em posição de travamento de sílaba tônica (meio e final de palavra) por falantes curitibanos;

ii. Verificar se há características diferentes ou mudanças acústicas nesta produção em relação a grupos etários de gerações distintas;

iii. Verificar se a natureza da vogal condiciona ou não a realização do rótico;

iv. Descrever acusticamente a realização da variante retroflexa nos dados de fala coletados, visando a estabelecer uma relação com descrições futuras ou já feitas desse som em outros dialetos do PB e para outras línguas. 
A fim de contemplar esses objetivos, foi realizado um experimento-piloto com seis falantes curitibanos (todos nascidos, criados e moradores de Curitiba, sendo quatro deles também filhos de curitibanos), em que róticos apareciam em palavras-alvo nas posições de travamento de sílaba tônica medial e final, em vocábulos dissílabos paroxítonos e oxítonos, sucedendo às vogais orais [a], [i] e [o]. As justificativas para as variáveis escolhidas e um maior detalhamento do design experimental serão dados na Seção 3. O parâmetro acústico medido foi frequência dos três primeiros formantes dos segmentos em questão, quando possível. Além disso, observou-se a influência da vogal precedente sobre a realização dos róticos. Os dados foram colhidos em estúdio acusticamente tratado. Como esperado, encontraram-se várias ocorrências da aproximante retroflexa, mas também do tap e da aproximante alveolar.

Na próxima seção, apresentaremos algumas descrições acústicas de róticos disponíveis na literatura fonética que serão base para nossa descrição acústica dos róticos no dialeto curitibano. Em seguida, na Seção 3, descreveremos a metodologia de coleta dos dados e o experimento-piloto. Na Seção 4, apresentaremos os dados coletados, procedendo à sua análise e discussão. Na última seção, apresentaremos os resultados e as conclusões a que chegamos a partir das discussões sobre o conjunto total de dados estudados.

\section{ESTUDOS JÁ REALIZADOS}

Segundo Ladefoged \& Maddieson (1996), os róticos são sons bastante frequentes: cerca de setenta e cinco por cento de todas as línguas consideradas pelos autores apresentam alguma realização dessa classe. Em termos representativos, o termo rótico acaba por remeter mais a questões gráficas (o grafema $R$ é utilizado para representar esta classe de sons em grande parte das línguas) do que a questões fonéticas, já que os róticos se comportam de maneira diferenciada por serem produzidos com pontos e modos de articulação diversos. Sendo assim, esperar-se-ia que a similaridade entre os membros da classe dos róticos se devesse mais a características auditivas e acústicas do que a características articulatórias. Entretanto, conforme já apresentado, Lindau (1985) demonstra que, mesmo em termos acústicos, não é possível encontrar uma única propriedade física que possa ser tomada como definidora dos róticos, ainda que eles efetivamente pareçam ter algum tipo de relação, já que, como apontara Lehiste (1962, p.109), “os vários membros do grupo são mais similares entre eles do que qualquer um do grupo em relação a qualquer outro de outro grupo" (tradução livre). Em um raciocínio similar, Lindau (op. cit.) propõe, então, que os róticos sejam descritos em termos de semelhança familiar, i.e. alguns membros se parecem com outros em relação a alguma propriedade, mas não é a mesma propriedade que é semelhante para todos os membros da família.

Para o PB, não há muitas descrições acústicas desta classe, ou de algumas de suas realizações. Podemos elencar, junto aos trabalhos de Ferraz (2005) e Clemente (2009), os estudos de Silva (1996, 1999, 2002) e Nishida (2009). Quanto à produção da variante retroflexa, além de alguns dos trabalhos supracitados, cabe apontar o importante e pioneiro estudo de Lehiste (1962) acerca dos róticos do inglês norte-americano, e também o trabalho anteriormente citado de Lindau (1985). Como, no experimento-piloto realizado para o presente estudo, as 
variantes de róticos encontradas foram o tap, a aproximante alveolar e a aproximante retroflexa, apenas elas serão abordadas.

O tap (ou tepe, em grafia adaptada) é uma das variantes de róticos mais frequentes nas línguas do mundo (Ladefoged \& Maddieson, 1996). De acordo com esses autores, esse som resulta articulatoriamente de um breve contato entre a ponta da língua e a região dental ou dos alvéolos; acusticamente, seu correlato costuma ser um momento de quase silêncio, decorrente do contato entre língua e região alveolar/dental, seguido da soltura do ar, à semelhança da explosão (estouro) característica de oclusivas (Silva, 1999).

A aproximante alveolar, por sua vez, decorre de uma aproximação dos articuladores (nesse caso, língua e alvéolos), sem que haja realmente contato entre eles. Como não há oclusão, mesmo que a constrição seja severa, o sinal acústico é contínuo e a trajetória de formantes permanece visível (Ladefoged \& Maddieson, 1996).

Já a aproximante retroflexa caracteriza-se pela elevação da parte inferior do dorso da língua em direção à região alveolar, enquanto a ponta da língua se curva para trás (Silva, 2002). Não há contato, mas sim uma aproximação dos articuladores (o que, em princípio, diferencia a aproximante retroflexa do retroflexo propriamente dito). Além dessa aproximação, há tendência à constrição faríngea e ao arredondamento labial (Ladefoged \& Maddieson, 1996).

Silva (2002) já apontara para a existência de alofonia gradiente em róticos na posição inicial, gradiência esta que só pode ser explicada dentro de um modelo que incorpore a noção de tempo intrínseco, uma vez que modelos de tempo extrínseco trabalham com alofonias de maneira categórica. A alofonia gradiente, conforme descrita por Clemente (2009), se estabelece entre duas categorias - para os dados do autor, entre o tap e a aproximante retroflexa. Certas condições podem favorecer a produção de um ou outro extremo, ou então gerar produções intermediárias que, em geral, se aproximam mais de um ou do outro polo. A força de fronteira forte causada por um vocativo em uma sentença imperativa, por exemplo, favoreceu a produção da aproximante retroflexa, enquanto a força de fronteira fraca entre um sujeito e o seu verbo acrescida de este verbo começar por vogal é uma situação que elicita o tap. Conforme será descrito na Seção 4, o mesmo panorama se colocou para os nossos dados.

Outro aspecto relevante para a descrição dos róticos é a influência das vogais adjacentes. Silva (1996) já encontrara efeitos de coarticulação entre líquidas e tônicas, e Ferraz (2005) demonstrou o mesmo para a aproximante retroflexa. Antes de abordar este trabalho, no entanto, convém se apresentar o trabalho de Lehiste (1962) para o retroflexo do inglês norteamericano.

Em seu trabalho, Lehiste (1962) analisou ocorrências de /r/ no inglês norte-americano do Meio Oeste nas posições inicial, medial e final, a partir de dados coletados de 5 informantes do sexo masculino. Ela constatou que havia duas características comuns aos róticos produzidos nesse dialeto: valores baixos para F3, e uma separação pequena de frequência entre F2 e F3. A autora hipotetiza que um possível correlato articulatório para essas propriedades seja a retroflexão.

Ferraz (2005), por sua vez, conduziu um estudo descritivo sobre a aproximante retroflexa realizada por falantes da cidade de Pato Branco/PR, com o intuito de verificar se os correlatos 
acústicos de tal som para o $\mathrm{PB}$ eram os mesmos do que aqueles apontados para outros dialetos/línguas. Como demonstrou o autor, diferentemente do que havia sido apontado por Lehiste (1962) para o retroflexo norte-americano, o F3 do retroflexo de Pato Branco não é "exatamente baixo, mas bemolizado". Isso significa que há um abaixamento dos valores do terceiro formante do rótico em relação ao mesmo formante da vogal que o precede, mas sem que o valor do formante precise necessariamente ser baixo em termos absolutos (e.g. abaixo de $2000 \mathrm{~Hz}$ ). Assim, ainda que o F3 efetivamente se apresente em torno de $2000 \mathrm{~Hz}$ ou inferior a isto para as vogais posteriores, ele é significativamente mais alto para vogais anteriores, mesmo apresentando uma bemolização. Clemente (2009) confirma esse traço como característico da retroflexão em PB, indicando que, quanto maior a queda de F3, maior será o grau de retroflexão.

Diante do que foi registrado pelos estudos citados anteriormente e considerando o pouco número de estudos específicos voltados à descrição e análise acústica do retroflexo no $\mathrm{PB}$, cabem as seguintes questões: haveria diferenças na realização do rótico em posição de travamento de sílaba tônica em posição medial e final no dialeto curitibano? Há influência da vogal precedente na realização do rótico - e, especialmente, do retroflexo? Há características diferentes ou mudanças acústicas nessa produção em relação a grupos etários de gerações distintas? Em caso positivo, como se dá, e em que proporção? Este trabalho procurará fornecer pistas para algumas dessas questões.

\section{METODOLOGIA}

Ao buscar descrever os róticos no dialeto curitibano, partimos da hipótese de que existiria a produção do retroflexo em posição de coda, e de que essa produção seria mais frequente na fala da geração jovem (20-25 anos) do que na fala de informantes de uma geração anterior (55-60 anos). Assim, reduzimos a abrangência deste estudo-piloto para a posição de coda, uma vez que interessava-nos tentar descrever acusticamente como se processa a produção do retroflexo (ou aproximante retroflexa) no dialeto curitibano e, consequentemente, no PB (ainda que seja apenas uma de suas possíveis realizações).

Todos os dados foram colhidos na cidade de Curitiba/PR. Optou-se pela fala de laboratório, ou seja, as palavras-alvo foram inseridas em sentenças-veículo e lidas pelos informantes para gravação em estúdio. Os dados colhidos foram então submetidos à análise acústica - para a qual se utilizou o software Praat $^{2}$-, objetivando principalmente verificar medidas de frequência dos três primeiros formantes dos róticos, bem como a influência ou não da vogal adjacente, com o intuito de buscar uma caracterização acústica desses sons para o dialeto escolhido.

Dado que um dos objetivos deste trabalho era observar se há uma tendência de disseminação do retroflexo hoje na fala de jovens curitibanos, em relação à fala de gerações anteriores,

\footnotetext{
${ }^{1}$ Traço proposto por Jakobson, Fant \& Halle (1952), remetendo ao abaixamento brusco ou enfraquecimento de componentes de alta frequência (FERRAZ, 2005).

${ }^{2}$ O software Praat é desenvolvido por Paul Boersma e David Weenink no Instituto de Ciências Fonéticas da Universidade de Amsterdã (disponível livremente em http://www.fon.hum.uva.nl/praat).
}

Work. Pap. Linguíst., 15(1): 136-154, Florianópolis, jan/abr, 2014 
nosso experimento-piloto consistiu na gravação de seis informantes, divididos em duas faixas etárias. Conforme o Quadro 1, a seguir, o primeiro grupo era composto por pessoas (2 do sexo masculino e 1 do sexo feminino) de idade entre 20 e 25 anos. O segundo grupo era composto por pessoas ( 1 do sexo masculino e 2 do sexo feminino) de idade entre 55 e 60 anos.

\begin{tabular}{|c|c|c|c|c|}
\hline Informante & Idade & Sexo & Escolaridade & Naturalidade \\
\hline $\mathrm{A}$ & 25 & $\mathrm{M}$ & Superior & Curitiba \\
\hline $\mathrm{B}$ & 24 & $\mathrm{M}$ & Superior & Curitiba \\
\hline $\mathrm{C}$ & 23 & $\mathrm{~F}$ & Superior & Curitiba \\
\hline $\mathrm{X}$ & 60 & $\mathrm{M}$ & Superior & Curitiba \\
\hline $\mathrm{Y}$ & 55 & $\mathrm{~F}$ & Superior & Curitiba \\
\hline $\mathrm{Z}$ & 59 & $\mathrm{~F}$ & Superior & Curitiba \\
\hline
\end{tabular}

Solicitou-se aos informantes que lessem um conjunto de 18 sentenças curtas elaboradas especialmente para este experimento, no formato "falo __ pra ele". As palavras, conforme já apresentado, consistiam em vocábulos dissílabos paroxítonos e oxítonos, com róticos em coda nas sílabas tônicas (conforme o Quadro 2, a seguir). Os distratores foram escolhidos na proporção de dois para um. Foram feitas 5 repetições do mesmo conjunto, porém com as sentenças aleatorizadas de maneira diferente, para evitar possíveis efeitos de memorização. $\mathrm{O}$ experimento foi realizado em estúdio sonoramente tratado na UFPR, para minimizar possíveis ruídos.

\begin{tabular}{|c|c|c|c|c|}
\hline Acento & Posição & Vogais & Palavra-alvo & Distratores \\
\hline \multirow{2}{*}{ Paroxítona } & \multirow{2}{*}{$\begin{array}{c}\text { Coda silábica } \\
\text { em meio de } \\
\text { palavra }\end{array}$} & {$[\mathrm{o}]$} & força & fosco; fonte \\
\cline { 3 - 5 } & & {$[\mathrm{i}]$} & firma & cisma; filme \\
\cline { 3 - 5 } Oxítona & \multirow{2}{*}{\begin{tabular}{c} 
Coda silábica \\
em final de \\
\cline { 3 - 5 }
\end{tabular}} & {$[\mathrm{a}]$} & tarde & casco; balde \\
\cline { 3 - 5 } & palavra & {$[\mathrm{i}]$} & calor & canhão; anzol \\
\cline { 3 - 5 } & & {$[\mathrm{a}]$} & vizir & visão; funil \\
\hline
\end{tabular}

Quadro 2 - Palavras-alvo e distratores

$\mathrm{Na}$ montagem do corpus, evitou-se o uso de logatomas, pois poderiam provocar estranhamento e diferenças na naturalidade da realização do rótico. Também evitamos as possíveis situações de apagamento do /r/, como formas de infinitivos verbais. Decidiu-se, 
assim, por usar nomes comuns na língua, e de uso mais corriqueiro. No entanto, é preciso observar, como será discutido adiante, que palavras como tarde e calor, por serem de uso muito frequente, possam ter favorecido o apagamento ou uma hipoarticulação do rótico. Também é preciso notar que a palavra vizir talvez tenha funcionado como um logatoma, já que aparentemente os informantes pareciam desconhecer seu significado. Com o intuito de verificar uma possível influência ou condicionamento da natureza da vogal em relação à realização do rótico, selecionamos também palavras que contivessem, antecedendo o som, cada uma das vogais orais que pretendíamos observar: [a]; [i] e [o] $]^{3}$.

Buscando uma caracterização fonético-acústica para a realização dos róticos (especialmente, do retroflexo) e, baseando-se na Teoria Acústica de Produção de Fala (Fant, 1960), considerou-se a fala semi-espontânea como um instrumento eficaz na coleta de dados e que cumpre os objetivos do estudo. Acredita-se, portanto, que este experimento, por mais que seja apenas um piloto, pode fornecer resultados consistentes que forneçam alguma contribuição para futuras descrições do comportamento fonético-acústico dos róticos e do retroflexo para outros dialetos do PB. Na próxima seção, serão analisados alguns espectrogramas dos dados colhidos e suas respectivas formas de onda para exemplificar os segmentos realizados pelos informantes.

\section{ANÁLISE E DISCUSSÃO DOS DADOS}

Como já dito anteriormente, encontraram-se três formas de róticos em posição de coda silábica no dialeto curitibano: tap, aproximante alveolar e aproximante retroflexa. $\mathrm{Na}$ verdade, uma descrição mais fiel seria a de que se encontrou um cenário de alofonia gradiente próximo daquele apontado por Clemente (2009): o tap e a aproximante retroflexa aparentam ser extremidades de um contínuo, em que a aproximante alveolar é um dos pontos, mas no qual também há muitos outros:

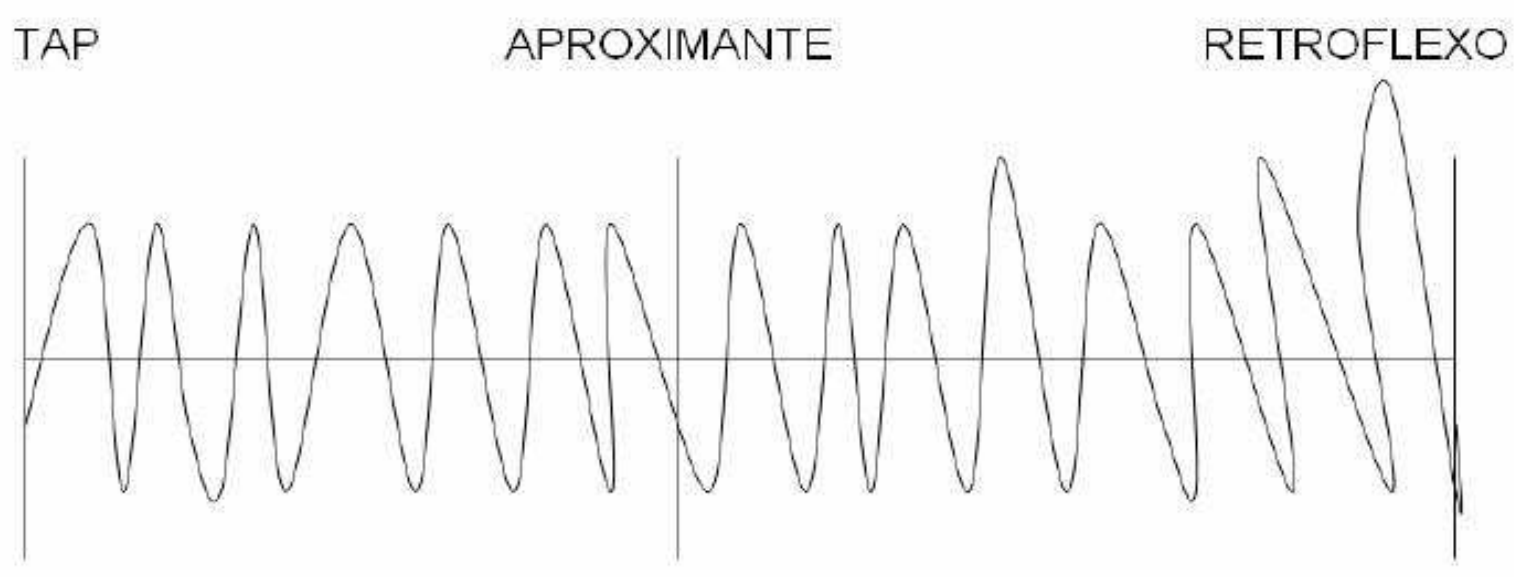

Figura 1 - Desenho ilustrativo da distribuição da alofonia gradiente (CLEMENTE, 2009)

\footnotetext{
${ }^{3}$ Acabamos decidindo pelo uso de [o], ao invés de [u], pela falta de palavras oxítonas que apresentassem essa vogal seguida de rótico.
} 
Não será realizado levantamento estatístico dos dados colhidos por duas questões: primeiro, por este tratar-se de um estudo-piloto, de modo que se perceberam muitas falhas que precisariam ser corrigidas em uma versão definitiva; segundo, pelas mesmas razões apontadas por Clemente (2009): devido ao caráter gradiente dos dados, agrupá-los em categorias seria apenas uma aproximação muito rudimentar, e uma estatística fiel à gradiência exigiria uma quantidade muito maior de realizações. Da mesma maneira que Clemente, também não serão utilizados os símbolos do IPA e assim, nos espectrogramas, indicaremos a ocorrência do rótico com apenas um $r$.

Em termos gerais, pode-se dizer que todos os sujeitos produziram variantes que se aproximavam das três categorias de sons acima nomeadas, i.e. tap, aproximante alveolar e aproximante retroflexa. Alguns dos sujeitos executaram manobras de retroflexão consistentemente e em todas as condições, enquanto outros só produziram a aproximante retroflexa quando o rótico era antecedido pela vogal posterior ([o]). No mesmo sentido, a condição em que o retroflexo foi menos produzido foi quando o rótico sucedia a vogal anterior [i], contexto em que os informantes alternaram entre o uso da aproximante alveolar ou do tap. Apenas o sujeito X produziu o retroflexo mesmo nessa condição.

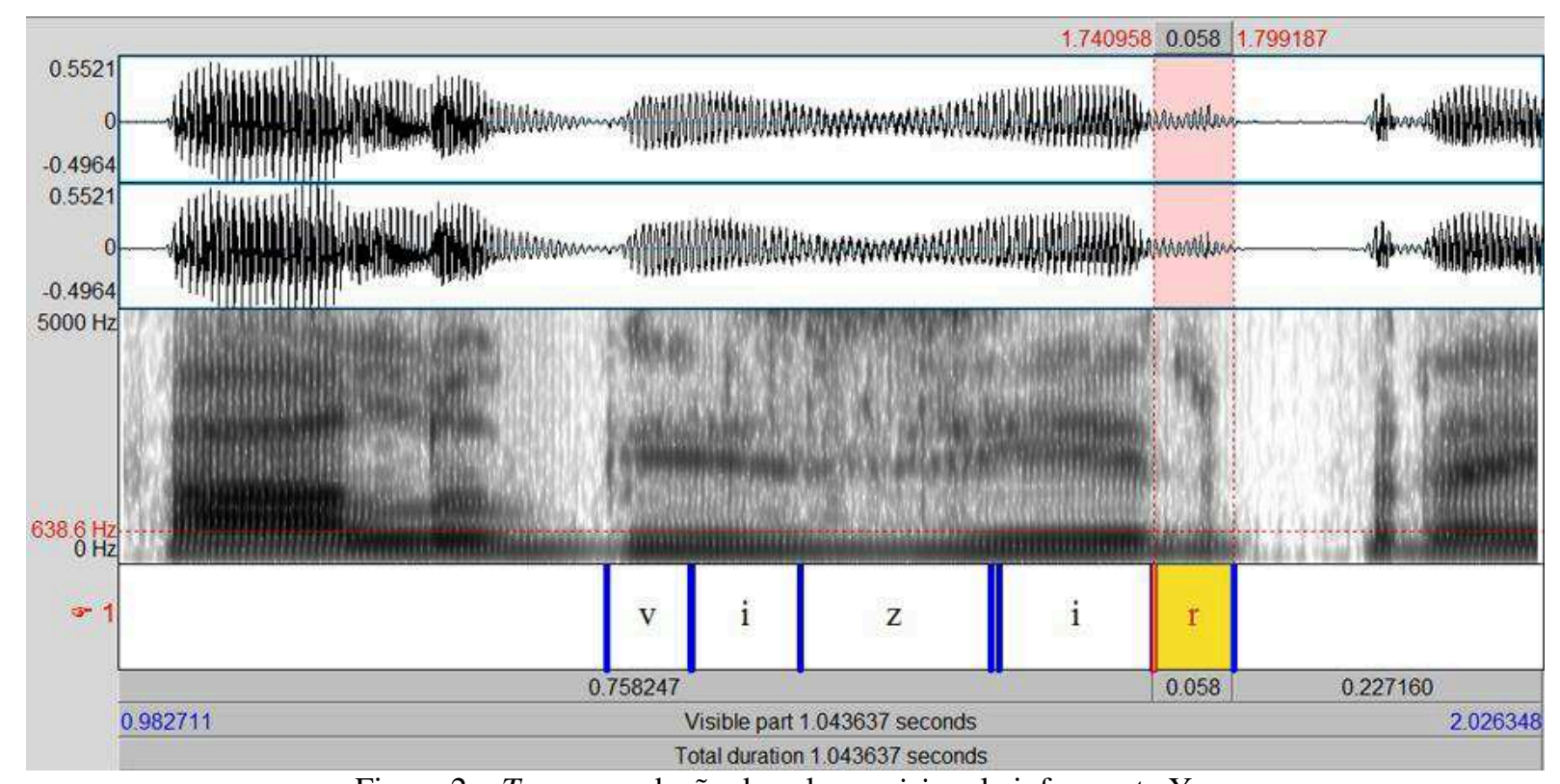

Figura 2 - Tap na produção da palavra vizir pela informante $\mathrm{Y}$ 
Uma característica observada na maior parte das produções de tap foi que, logo após a plosão, havia uma expiração, semelhante a um ruído fricativo, como se pode observar pela Figura 2.

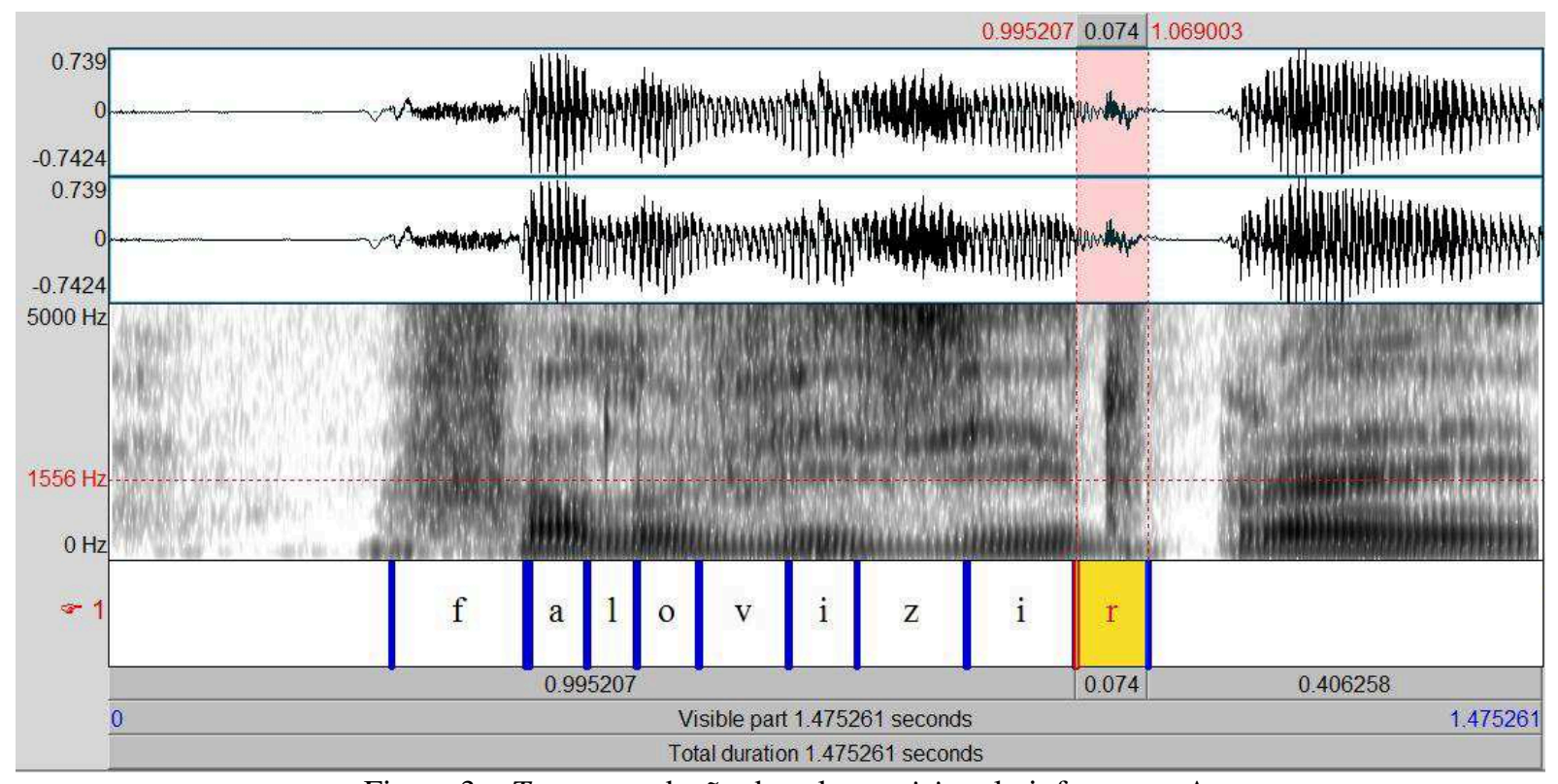

Figura 3 - Tap na produção da palavra vizir pelo informante A

Conforme podemos ver na parte selecionada da Figura 3, após o final do fechamento do tap se segue um breve momento de ruído (em torno de $36 \mathrm{~ms}$ ). Essa foi uma produção bastante comum para o tap entre os informantes.

A aproximante alveolar se caracteriza por um som parecido com o tap auditivamente, mas que no sinal acústico permanece contínuo e não apresenta o período de oclusão característico daquele som. Veja Figura 4.

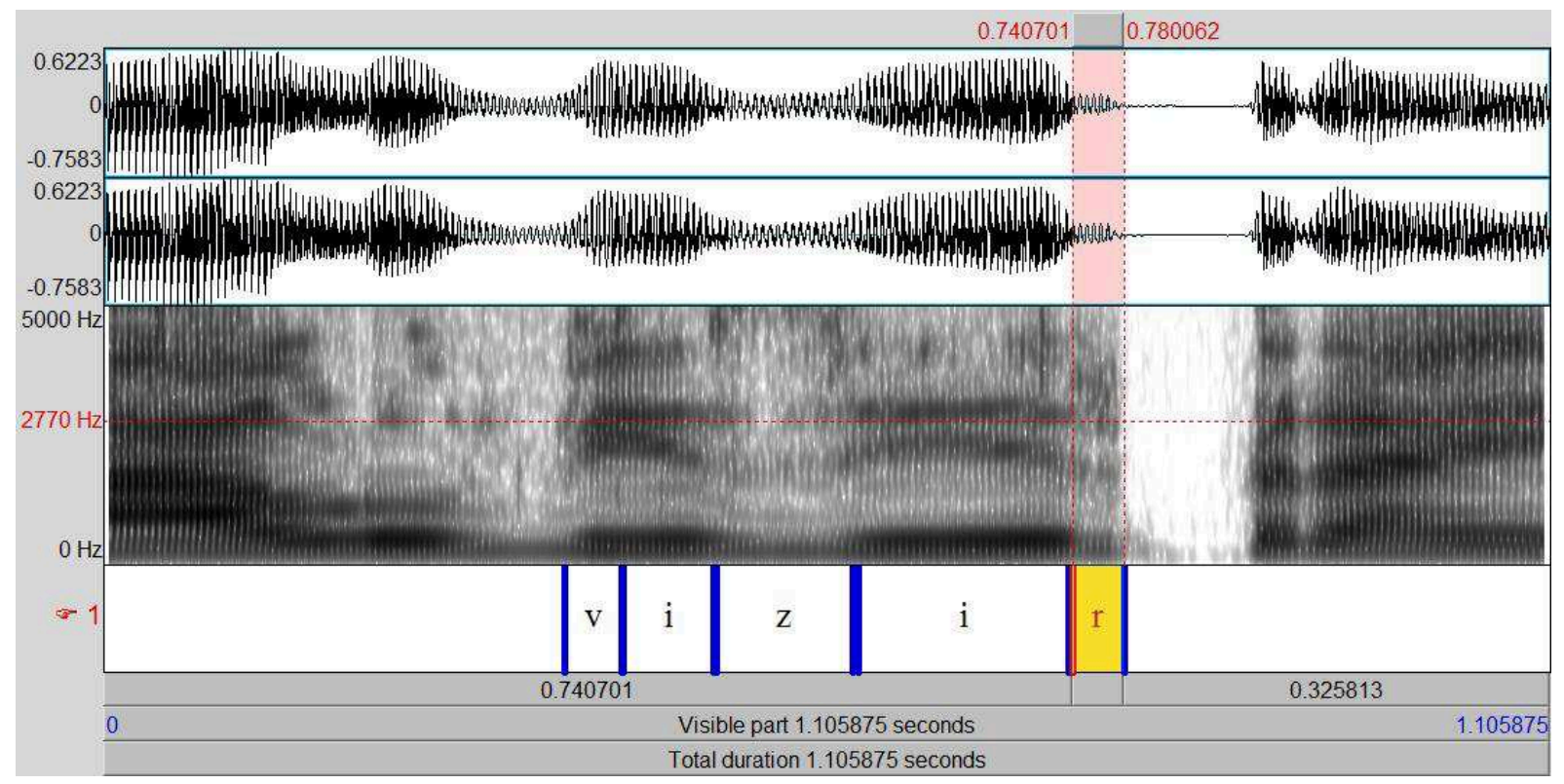

Figura 4 - Aproximante Alveolar na produção da palavra vizir pela informante $\mathrm{Z}$

Work. Pap. Linguíst., 15(1): 136-154, Florianópolis, jan/abr, 2014 
Há que se apontar que talvez deva ser levada em consideração para próximos estudos a variável sexo, já que a produção retroflexa foi mais comum entre os homens do que entre as mulheres. De fato, as falantes $\mathrm{C}$ e $\mathrm{Z}$ produziram a aproximante retroflexa em bem menos quantidade do que os demais informantes (a informante $\mathrm{Y}$ produziu um pouco mais), utilizando, nos contextos em que a aproximante retroflexa foi utilizada pelos homens, a aproximante alveolar. O quadro a seguir explicita, em dados percentuais, a produção dos diferentes róticos:

\begin{tabular}{|c|c|c|c|c|c|}
\hline Geração & Informante & Tap & $\begin{array}{c}\text { Aproximante } \\
\text { retroflexa }\end{array}$ & $\begin{array}{c}\text { Aproximante } \\
\text { alveolar }\end{array}$ & $\begin{array}{c}\text { Apagamento } \\
\text { do rótico }\end{array}$ \\
\hline \multirow{3}{*}{ Mais jovem } & $\mathrm{A}$ (masculino) & $34,5 \%$ & $44,8 \%$ & $20,7 \%$ & $0 \%$ \\
\cline { 2 - 6 } & $\mathrm{B}$ (masculino) & $0 \%$ & $73,3 \%$ & $6,6 \%$ & $20 \%$ \\
\cline { 2 - 6 } & $\mathrm{C}$ (feminino) & $27,5 \%$ & $31 \%$ & $20,7 \%$ & $20,7 \%$ \\
\hline \multirow{3}{*}{ Mais velha } & $\mathrm{X}$ (masculino) & $16,6 \%$ & $80 \%$ & $3,4 \%$ & $0 \%$ \\
\cline { 2 - 6 } & $\mathrm{Y}$ (feminino) & $23,3 \%$ & $66,6 \%$ & $0 \%$ & $10 \%$ \\
\cline { 2 - 6 } & $\mathrm{Z}$ (feminino) & $23,3 \%$ & $36,6 \%$ & $33,3 \%$ & $6,6 \%$ \\
\hline
\end{tabular}

Quadro 3 - Produção dos róticos em dados percentuais

Também foram encontrados casos de apagamento do rótico, ou casos em que ele não é identificável a partir do sinal acústico. Isso ocorreu especialmente na palavra lugar, em que 3 dos informantes (B, C e Z) fizeram o apagamento de maneira consistente. Para os informantes $\mathrm{B}, \mathrm{C}$ e $\mathrm{X}$, ainda, a adjacência do rótico à vogal anterior [i] pareceu ser um contexto que também favoreceu o apagamento, especialmente quando a sílaba encontrava-se em posição medial. Para verificar se efetivamente houve o apagamento, entretanto, seria necessário realizar um novo experimento com pares mínimos do tipo firma-fima (exemplo apenas ilustrativo, pois seria necessário pensar em palavras reais e mais adequadas), para que fosse possível observar se há ou não influência de rótico nos sons adjacentes.

Há ainda que se notar a produção do tap retroflexo, conforme apontado por Ferraz (2005), como exemplificado pela Figura 5. 


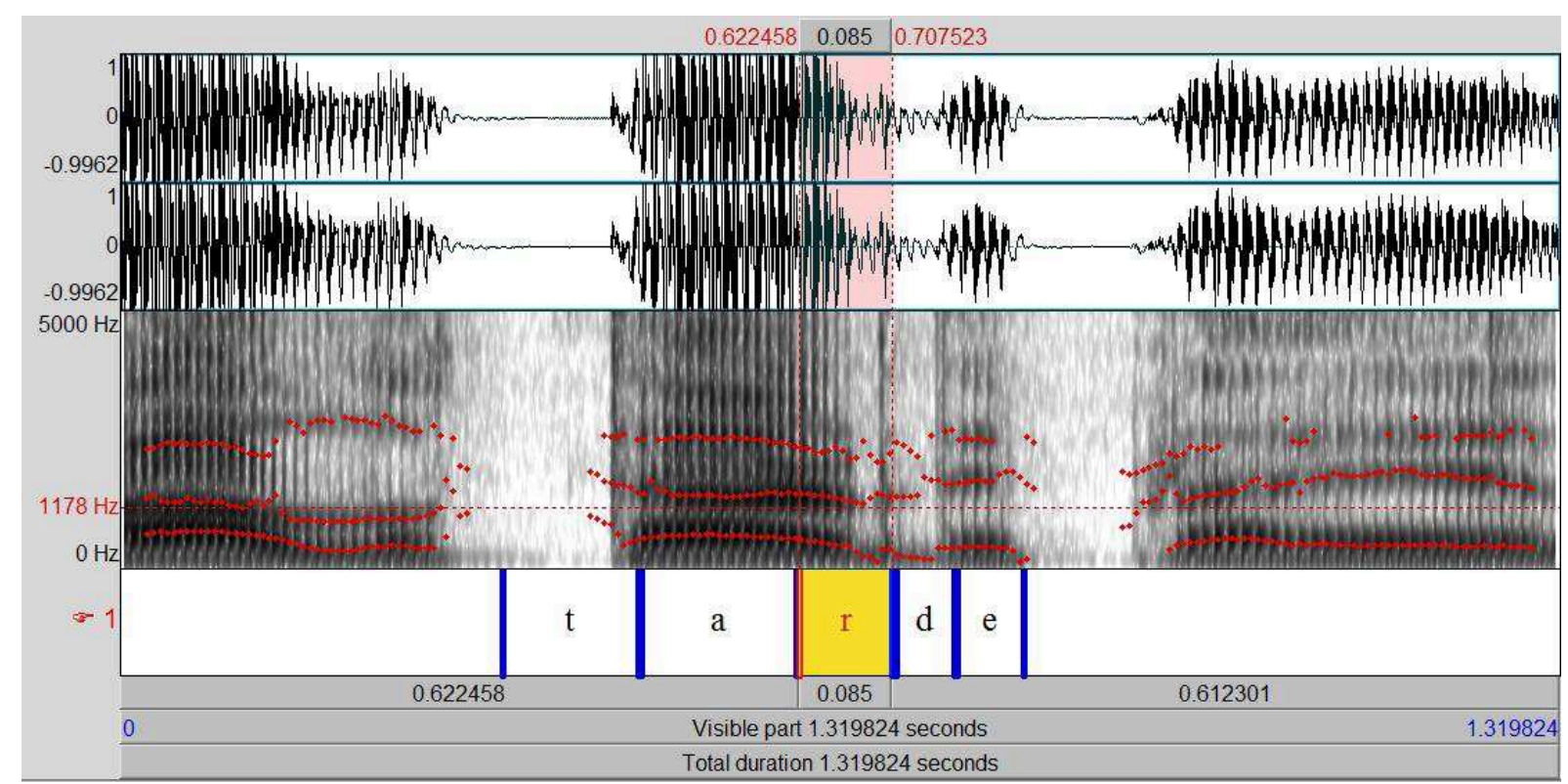

Figura 5 - Tap retroflexo na produção da palavra tarde pelo informante $\mathrm{X}$

Como se pode perceber pela imagem, exibida na Figura 5, há uma queda de F3 que é contínua com a vogal e que se relaciona com a retroflexão; entretanto, a essa queda se sucede a produção clara de um tap.

Na produção da aproximante retroflexa, pode-se falar em graus de retroflexão. Houve casos em que a queda de F3 foi brusca, situação na qual a retroflexão foi audivelmente mais perceptível (Figura 6). Quando o abaixamento de F3 era mais suave, no entanto, a produção situava-se no limiar entre a aproximante retroflexa e a aproximante alveolar (Figura 7).

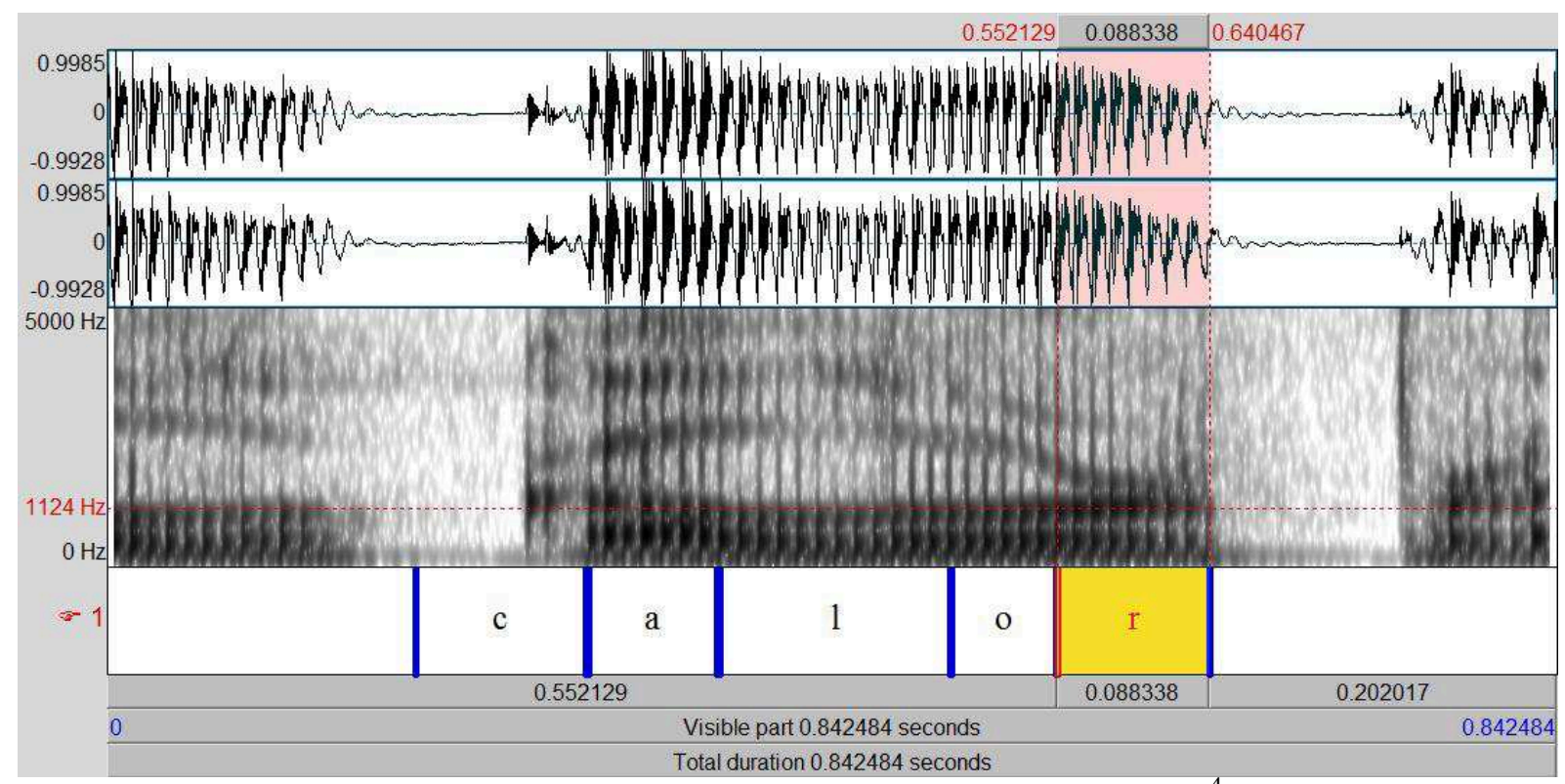

Figura 6 - Retroflexo na produção da palavra calor pelo informante $\mathrm{X}^{4}$

\footnotetext{
${ }^{4}$ A segmentação neste quadro e no seguinte é apenas aproximada, uma vez que é bastante difícil decidir em que pontos segmentar tanto a lateral quanto o retroflexo, já que estes apresentam graus de coarticulação com a vogal tônica.
} 


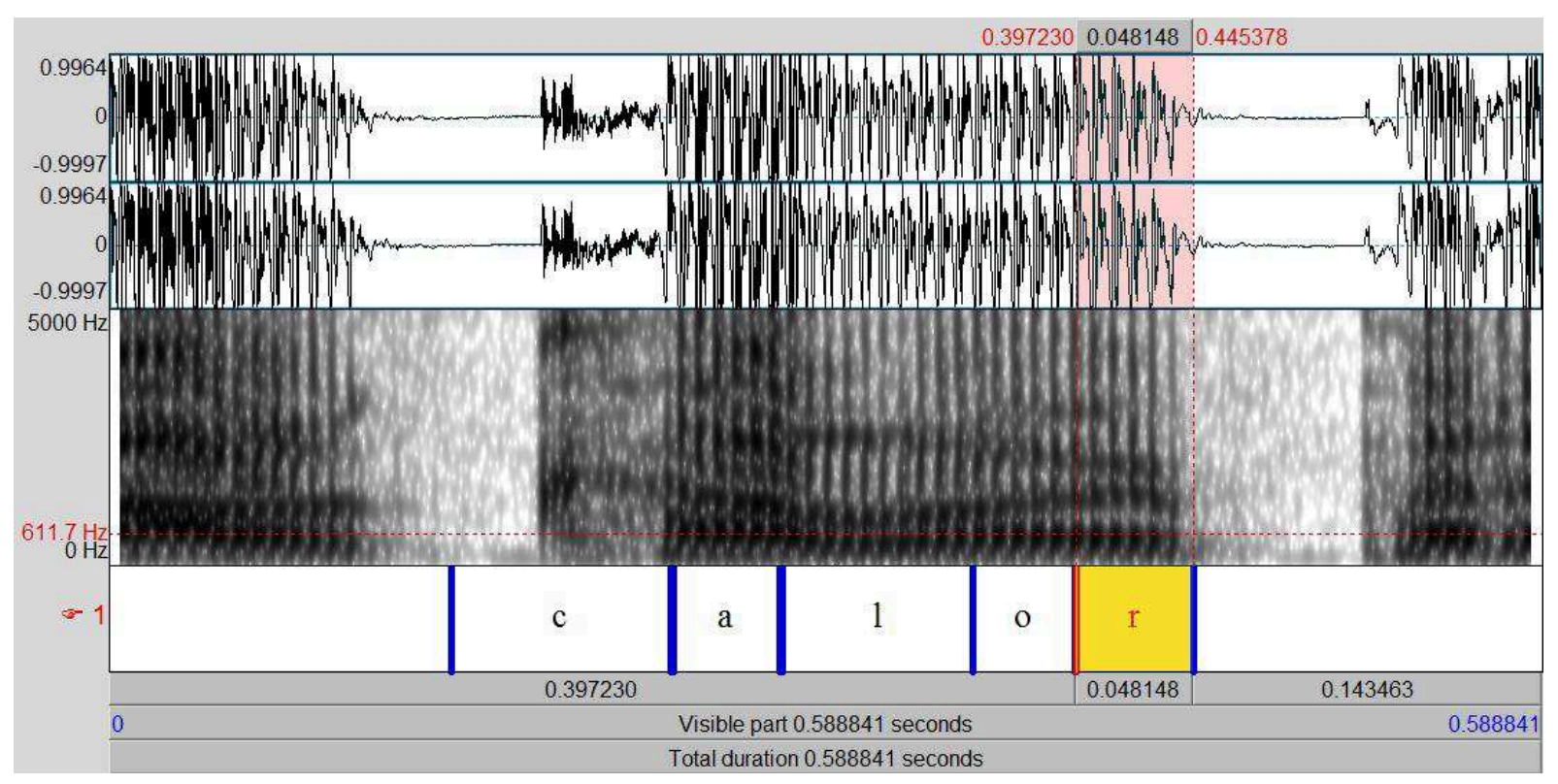

Figura 7 - Retroflexo leve na produção da palavra calor pelo informante B

Como pode ser observado na Figura 6, a queda de F3 é bastante acentuada, ficando o formante com valor abaixo de $1800 \mathrm{~Hz}$. Na Figura 7, esse abaixamento é mais suave, e o valor de F3 situa-se em torno de $2000 \mathrm{~Hz}$. Independentemente do valor absoluto que o formante atinge, a retroflexão parece efetivamente estar associada ao traço bemolizado de F3, conforme apontara Ferraz (2005); e, como já dito, quanto maior a queda no valor do formante em relação ao formante da vogal adjacente, maior o grau de retroflexão que se apresenta no rótico. No entanto, é importante notar que, diferentemente dos dados encontrados pelo autor, nas produções de retroflexo coletadas em nosso experimento, foram verificados valores de F3 abaixo (ou em torno) de $2000 \mathrm{~Hz}$ (para os falantes homens) para todas as condições (vogal anterior, central e alta), o que coloca a questão de se o retroflexo encontrado entre esses falantes se aproximaria mais do retroflexo norte-americano descrito por Lehiste (1962).

Não se perceberam, como também já observara Ferraz (2005), diferenças entre a produção do rótico na posição medial e final, à exceção do aspecto de duração do rótico, que em posição medial se mostrou, de maneira geral, muito mais breve, dificultando sua segmentação. Ainda, a sequência rótico + nasal na palavra-alvo firma se mostrou problemática para a análise, uma vez que a nasal parece afetar os segmentos que a cercam. Dessa forma, talvez fosse mais interessante, para estudos futuros, escolher vocábulos que apresentassem rótico seguido de oclusiva (como a palavra-alvo tarde), já que, nesse caso, a produção do rótico se torna mais destacada.

\section{CONSIDERAÇÕES FINAIS}

\footnotetext{
${ }^{5} \mathrm{O}$ falante $\mathrm{B}$ foi o único a produzir róticos com valores de $\mathrm{F} 3$ maiores do que $2100 \mathrm{~Hz}$ que ainda puderam ser identificadas como aproximantes retroflexas no contexto da vogal anterior [i].
} 
Para este trabalho, estabelecemos quatro objetivos específicos: descrever a realização dos róticos em posição de travamento de sílaba tônica medial e final no dialeto curitibano; verificar se havia diferença na produção em relação à idade dos informantes; confirmar o condicionamento do rótico em relação à vogal precedente; e descrever acusticamente a realização da variante retroflexa.

Conforme apresentado ao longo deste estudo, foi encontrado um quadro similar àquele já apresentado por Clemente (2009): há, em Curitiba, alofonia gradiente entre o tap e a aproximante retroflexa, alofonia que, para os dados deste experimento-piloto, foi condicionada pelo contexto vocálico - influência que já fora apontada por Silva (1996) e Ferraz (2005). Quando o rótico sucedia vogais posteriores, havia uma tendência à produção da aproximante retroflexa - possivelmente porque, como bem observou Clemente (2009), as vogais posteriores (especialmente o [u], mas também o [o]) compartilham semelhanças com o retroflexo, já que são produzidas através da retração do dorso de língua. Em contextos de vogal anterior, a produção do tap era privilegiada. Quanto à vogal central, apresentou-se variação entre os informantes: para alguns deles, houve aparentemente um favorecimento para a produção da aproximante retroflexa, mas não para outros. Isso levanta a questão de se a vogal "central" seria ou não um pouco posteriorizada em $\mathrm{PB}$, ou se haveria variação em sua produção entre os falantes. Para verificar essa hipótese, no entanto, teria sido necessário analisar a ocorrência das vogais tônicas independentemente, e analisar se sua produção apresentava ou não traços de posteriorização.

Diferentemente do que havia sido estabelecido como hipótese, não foi encontrada diferença geracional na produção da aproximante retroflexa: ao contrário, o informante que produziu essa variante de maneira mais sistemática foi justamente o falante $\mathrm{X}$, de 60 anos. Dessa forma, presume-se que a aproximante retroflexa já faça parte do dialeto curitibano há mais tempo do que se imaginava, uma vez que esse falante tem, inclusive, pais nascidos em Curitiba. Uma variável não prevista que pareceu exercer algum peso, porém, foi a de sexo: aparentemente, as falantes do sexo feminino tenderam a produzir mais a aproximante alveolar que a aproximante retroflexa, em contraste com os falantes do sexo masculino. Para verificar tanto um como o outro resultado, entretanto, seria necessário um estudo sociolinguístico mais cuidadoso, que levasse em conta outras variáveis, e um corpus mais amplo.

O contexto de aparente apagamento do rótico, também, precisa ser analisado com mais cuidado; um estudo que cotejasse sequências do tipo firma com outras do tipo fima (este exemplo é meramente ilustrativo) poderia nos indicar com mais precisão se há, ou não, traços que recuperem a produção no rótico em sequências de aparente apagamento. Ainda, percebeuse durante a execução do experimento a inadequação do vocábulo vizir, uma vez que, devido ao fato de essa ser uma palavra bastante incomum, os informantes a leram como logatoma, relativizando, portanto, os resultados que foram obtidos - já que a aparente tendência à produção de tap após a vogal anterior [i] nesse contexto pode ser resultado da hiperarticulação do som.

Quanto à variante retroflexa, os dados encontrados neste experimento corroboram os resultados de Ferraz (2005) quanto ao correlato da aproximante retroflexa em PB ser o traço bemolizado de F3. No entanto, os valores encontrados para F3 entre os falantes masculinos 
ficaram frequentemente bastante abaixo dos $2000 \mathrm{~Hz}$, o que levanta a pergunta de se haveria diferença entre a aproximante retroflexa produzida em Pato Branco e a produzida em Curitiba, e se a do dialeto curitibano talvez se aproximasse mais daquela descrita por Lehiste (1962) para o dialeto norte-americano.

Por fim, ainda que este estudo tenha sido apenas um piloto, acredita-se que os resultados encontrados possam apontar caminhos e fornecer boas bases para estudos futuros acerca dos róticos e do retroflexo no dialeto curitibano e no $\mathrm{PB}$.

\section{REFERÊNCIAS}

CLEMENTE, Felipe Costa. Retroflexão Gradiente nos Róticos em coda no PB de Curitiba. Dissertação (Mestrado em Letras) - Universidade Federal do Paraná, Curitiba, 2009.

FERRAZ, Irineu da Silva. Características Fonético-Acústicas do /R/Retroflexo do Português Brasileiro: Dados de Informantes de Pato Branco (PR). Dissertação (Mestrado em Letras) Universidade Federal do Paraná, Curitiba, 2005.

LADEFOGED, Peter; MADDIESON, Ian. Rhotics. In.: The Sounds of the World's Languages. Cambridge: Blackwell Publishers, 1996, p. 215-245.

LEHISTE, Ilse. Some Allophones of $/ \mathrm{r} /$ in American English. In: _. Acoustical Characteristics of Selected English Consonants. The Hague: Mouton, 1962, p 51-115.

LINDAU, Mona. The story of /r/. In: FROMKIN, Victoria A (org). Phonetic Linguistics: Essays in honor of Peter Ladefoged. New York: Academic Press, 1985, p. 157-168.

NISHIDA, Gustavo. 2009. A Natureza Intervocálica do Tap em PB. Dissertação (Mestrado em Letras) - Universidade Federal do Paraná, Curitiba.

SILVA, Adelaide Hercília Pescatori. Para a Descrição Fonético-Acústica das Líquidas no Português Brasileiro: dados de um informante paulistano. Dissertação (Mestrado em Linguística) - Instituto de Estudos da Linguagem, Universidade Estadual de Campinas, Campinas, 1996.

As Fronteiras entre Fonética e Fonologia e a Alofonia dos Róticos Iniciais em PB. Tese (Doutorado em Linguística) - Instituto de Estudos da Linguagem, Universidade Estadual de Campinas, Campinas, 2002.

Recebido em: 13/03/2014

Aceito em: 16/04/2014

\section{APÊNDICE}

\section{INFORMANTE A}




\begin{tabular}{|c|c|c|c|c|c|c|c|c|c|c|c|c|c|c|c|}
\hline & \multicolumn{3}{|c|}{ R1 } & \multicolumn{3}{|c|}{ R2 } & \multicolumn{3}{|c|}{ R3 } & \multicolumn{3}{|c|}{ R4 } & \multicolumn{3}{|c|}{ R5 } \\
\hline & F1 & F2 & F3 & F1 & F2 & F3 & F1 & F2 & F3 & F1 & F2 & F3 & F1 & F2 & F3 \\
\hline \multirow{2}{*}{ TARDE } & 505 & 1568 & 1982 & 490 & 1563 & 1916 & 539 & 1566 & 1931 & 468 & 1595 & 2213 & 543 & 1487 & 1975 \\
\hline & \multicolumn{3}{|c|}{ RETROFLEXO } & \multicolumn{3}{|c|}{ RETROFLEXO } & \multicolumn{3}{|c|}{ RETROFLEXO } & \multicolumn{3}{|c|}{ RETROFLEXO } & \multicolumn{3}{|c|}{ RETROFLEXO } \\
\hline \multirow{2}{*}{ FIRMA } & 281 & 1617 & 2379 & 334 & 1726 & 2291 & 327 & 1668 & 2225 & 382 & 1332 & 1898 & 342 & 1521 & 2244 \\
\hline & \multicolumn{3}{|c|}{ APROXIMANTE ALV. } & \multicolumn{3}{|c|}{ TAP } & \multicolumn{3}{|c|}{ APROXIMANTE ALV. } & \multicolumn{3}{|c|}{ RETROFLEXO } & \multicolumn{3}{|c|}{ APROXIMANTE ALV. } \\
\hline \multirow{2}{*}{ FORÇA } & 383 & 1165 & 1700 & 393 & 1179 & 1824 & 384 & 1165 & 1870 & 432 & 1193 & 1842 & \multirow{2}{*}{\multicolumn{3}{|c|}{ DADO INVÁLIDO }} \\
\hline & \multicolumn{3}{|c|}{ RETROFLEXO } & \multicolumn{3}{|c|}{ RETROFLEXO } & \multicolumn{3}{|c|}{ RETROFLEXO } & \multicolumn{3}{|c|}{ RETROFLEXO } & & & \\
\hline \multirow{2}{*}{ LUGAR } & 342 & 1371 & 2042 & 395 & 1390 & 2243 & 319 & 1307 & 2077 & 580 & 1391 & 2147 & 485 & 1369 & 1997 \\
\hline & \multicolumn{3}{|c|}{ APROXIMANTE ALV. } & \multicolumn{3}{|c|}{ APROXIMANTE ALV. } & \multicolumn{3}{|c|}{ TAP expirado } & \multicolumn{3}{|c|}{ TAP expirado } & \multicolumn{3}{|c|}{ RETROFLEXO } \\
\hline \multirow{2}{*}{ VIZIR } & 295 & 1662 & 2149 & 288 & 1693 & 2218 & 314 & 1665 & 2153 & 294 & 1655 & 2120 & 267 & 1467 & 2240 \\
\hline & \multicolumn{3}{|c|}{ TAP expirado } & \multicolumn{3}{|c|}{ TAP } & \multicolumn{3}{|c|}{ TAP expirado } & \multicolumn{3}{|c|}{ TAP expirado } & APRO & MANT & ALV. \\
\hline & 383 & 1079 & 1876 & 382 & 1157 & 2034 & 311 & 1145 & 1514 & 386 & 1187 & 2005 & 386 & 1267 & 1614 \\
\hline CALOR & & P expir & & & P expir & do & RETR & FLEXO & spirado & & $\begin{array}{l}\text { AP retr } \\
\text { expir }\end{array}$ & $\begin{array}{l}\text { flexo } \\
\text { lo }\end{array}$ & & ROFLE & \\
\hline
\end{tabular}

INFORMANTE B

\begin{tabular}{|c|c|c|c|c|c|c|c|c|c|c|c|c|c|c|c|}
\hline & \multicolumn{3}{|c|}{ R1 } & \multicolumn{3}{|c|}{$\mathbf{R 2}$} & \multicolumn{3}{|c|}{ R3 } & \multicolumn{3}{|c|}{ R4 } & \multicolumn{3}{|c|}{ R5 } \\
\hline & F1 & F2 & F3 & F1 & F2 & F3 & F1 & F2 & F3 & F1 & F2 & F3 & F1 & F2 & F3 \\
\hline \multirow{2}{*}{$\begin{array}{c}\text { TARD } \\
E\end{array}$} & 523 & $\begin{array}{c}165 \\
2\end{array}$ & 2080 & 565 & $\begin{array}{c}161 \\
1\end{array}$ & 2084 & 440 & 1605 & 2025 & 499 & 1599 & 2008 & 608 & 1547 & 1918 \\
\hline & \multicolumn{3}{|c|}{ RETROFLEXO } & \multicolumn{3}{|c|}{ RETROFLEXO } & \multicolumn{3}{|c|}{ RETROFLEXO } & \multicolumn{3}{|c|}{ RETROFLEXO } & \multicolumn{3}{|c|}{ RETROFLEXO } \\
\hline \multirow[t]{2}{*}{$\begin{array}{l}\text { FIRM } \\
\text { A }\end{array}$} & 362 & $\begin{array}{c}153 \\
0\end{array}$ & 2075 & \multirow{2}{*}{\multicolumn{3}{|c|}{ APAGADO }} & \multirow{2}{*}{\multicolumn{3}{|c|}{ APAGADO }} & \multirow{2}{*}{\multicolumn{3}{|c|}{ APAGADO }} & \multirow{2}{*}{\multicolumn{3}{|c|}{ APAGADO }} \\
\hline & \multicolumn{3}{|c|}{ APROX. ALV. } & & & & & & & & & & & & \\
\hline \multirow{2}{*}{$\begin{array}{c}\text { FORÇ } \\
\text { A }\end{array}$} & 478 & $\begin{array}{c}148 \\
2\end{array}$ & 2107 & 411 & $\begin{array}{c}143 \\
7\end{array}$ & 2157 & 446 & 1445 & 2038 & 406 & 1415 & 1933 & 430 & 1494 & 2044 \\
\hline & \multicolumn{3}{|c|}{$\begin{array}{c}\text { POUCO } \\
\text { RETROFLEXO }\end{array}$} & \multicolumn{3}{|c|}{$\begin{array}{c}\text { POUCO } \\
\text { RETROFLEXO }\end{array}$} & \multicolumn{3}{|c|}{ RETROFLEXO } & \multicolumn{3}{|c|}{ RETROFLEXO } & \multicolumn{3}{|c|}{ RETROFLEXO } \\
\hline \multirow{2}{*}{$\begin{array}{l}\text { LUGA } \\
\text { R }\end{array}$} & \multirow{2}{*}{\multicolumn{3}{|c|}{ APAGADO }} & \multirow{2}{*}{\multicolumn{3}{|c|}{ APAGADO }} & 524 & 1359 & 1912 & 538 & 1462 & 1941 & 555 & 1417 & 1898 \\
\hline & & & & & & & & ETROFL & XO & & TROFL & & & ROFL & \\
\hline \multirow{2}{*}{ VIZIR } & 350 & $\begin{array}{c}180 \\
2\end{array}$ & 2545 & 351 & $\begin{array}{c}164 \\
6\end{array}$ & 2198 & 352 & 1679 & 2176 & 389 & 1713 & 2315 & 372 & 1679 & 2282 \\
\hline & \multicolumn{3}{|c|}{ APROX. ALV. } & \multicolumn{3}{|c|}{ RETROFLEXO } & \multicolumn{3}{|c|}{ RETROFLEXO } & \multicolumn{3}{|c|}{ RETROFLEXO } & \multicolumn{3}{|c|}{ RETROFLEXO } \\
\hline $\begin{array}{c}\text { CALO } \\
\text { R }\end{array}$ & 474 & $\begin{array}{c}151 \\
3\end{array}$ & 2117 & 481 & $\begin{array}{c}135 \\
4\end{array}$ & 2074 & 459 & 1343 & 1992 & 429 & 1306 & 1928 & 429 & 1289 & 2032 \\
\hline
\end{tabular}


http://dx.doi.org/10.5007/1984-8420.2014v15n1p136

\begin{tabular}{|c|c|c|c|c|c|}
\hline & RETROFLEXO & $\begin{array}{c}\text { POUCO } \\
\text { RETROFLEXO }\end{array}$ & RETROFLEXO & RETROFLEXO & $\begin{array}{c}\text { POUCO } \\
\text { RETROFLEXO }\end{array}$ \\
\hline
\end{tabular}

INFORMANTE C

\begin{tabular}{|c|c|c|c|c|c|c|c|c|c|c|c|c|c|c|c|}
\hline & \multicolumn{3}{|c|}{ R1 } & \multicolumn{3}{|c|}{ R2 } & \multicolumn{3}{|c|}{ R3 } & \multicolumn{3}{|c|}{ R4 } & \multicolumn{3}{|c|}{ R5 } \\
\hline & F1 & F2 & F3 & F1 & F2 & F3 & F1 & F2 & F3 & F1 & F2 & F3 & F1 & F2 & F3 \\
\hline \multirow[b]{2}{*}{ TARDE } & 511 & 1952 & 2559 & \multirow{2}{*}{\multicolumn{3}{|c|}{ DADO INVÁLIDO }} & 364 & 1995 & 2918 & 414 & 1971 & 2911 & 619 & 1989 & 2639 \\
\hline & \multicolumn{3}{|c|}{ RETROFLEXO } & & & & \multicolumn{3}{|c|}{ APROX. ALV. } & \multicolumn{3}{|c|}{ APROX. ALV. } & \multicolumn{3}{|c|}{$\begin{array}{c}\text { POUCO } \\
\text { RETROFLEXO }\end{array}$} \\
\hline \multirow{2}{*}{ FIRMA } & 425 & 2001 & 2886 & 480 & 1989 & 2939 & 449 & 1718 & 2696 & 463 & 1995 & 2924 & 463 & 2118 & 2909 \\
\hline & \multicolumn{3}{|c|}{ TAP } & \multicolumn{3}{|c|}{ TAP } & \multicolumn{3}{|c|}{ APROX. ALV. } & \multicolumn{3}{|c|}{ TAP } & \multicolumn{3}{|c|}{ TAP } \\
\hline \multirow[b]{2}{*}{ FORÇA } & 458 & 1535 & 2572 & 285 & 1710 & 2497 & 434 & 1559 & 2565 & 472 & 1670 & 2541 & 467 & 1726 & 2323 \\
\hline & \multicolumn{3}{|c|}{$\begin{array}{l}\text { POUQUÍSSIMO } \\
\text { RETROFLEXO }\end{array}$} & \multicolumn{3}{|c|}{ POUCO RETROFLEXO } & \multicolumn{3}{|c|}{ POUCO RETROFLEXO } & \multicolumn{3}{|c|}{ TAP RETROFLEXO } & \multicolumn{3}{|c|}{ RETROFLEXO } \\
\hline \multirow[b]{2}{*}{ LUGAR } & \multirow{2}{*}{\multicolumn{3}{|c|}{ APAGADO }} & 614 & 1597 & 2513 & 620 & 1708 & 2735 & \multirow{2}{*}{\multicolumn{3}{|c|}{ APAGADO }} & \multirow{2}{*}{\multicolumn{3}{|c|}{ APAGADO }} \\
\hline & & & & \multicolumn{3}{|c|}{$\begin{array}{c}\text { Praticamente } \\
\text { apagado }\end{array}$} & \multicolumn{3}{|c|}{ TAP } & & & & & & \\
\hline \multirow[b]{2}{*}{ VIZIR } & 437 & 2065 & 2857 & 244 & 1941 & 2875 & 368 & 2186 & 2896 & 363 & 2161 & 2875 & \multirow{2}{*}{\multicolumn{3}{|c|}{ APAGADO }} \\
\hline & \multicolumn{3}{|c|}{ TAP } & \multicolumn{3}{|c|}{$\begin{array}{l}\text { Praticamente } \\
\text { apagado }\end{array}$} & \multicolumn{3}{|c|}{ APROX. ALV. } & & ROX. A & & & & \\
\hline & 542 & 1519 & 2866 & 448 & 1537 & 2822 & 481 & 1561 & 2545 & 530 & 1476 & 2613 & 411 & 1492 & 2764 \\
\hline CALOR & & PROX. & & & $\begin{array}{l}\text { QUÍSS } \\
\text { ROFL }\end{array}$ & & POUCC & RETRO & FLEXO & POUC & RETRC & FLEXO & & TAP & \\
\hline
\end{tabular}

INFORMANTE X

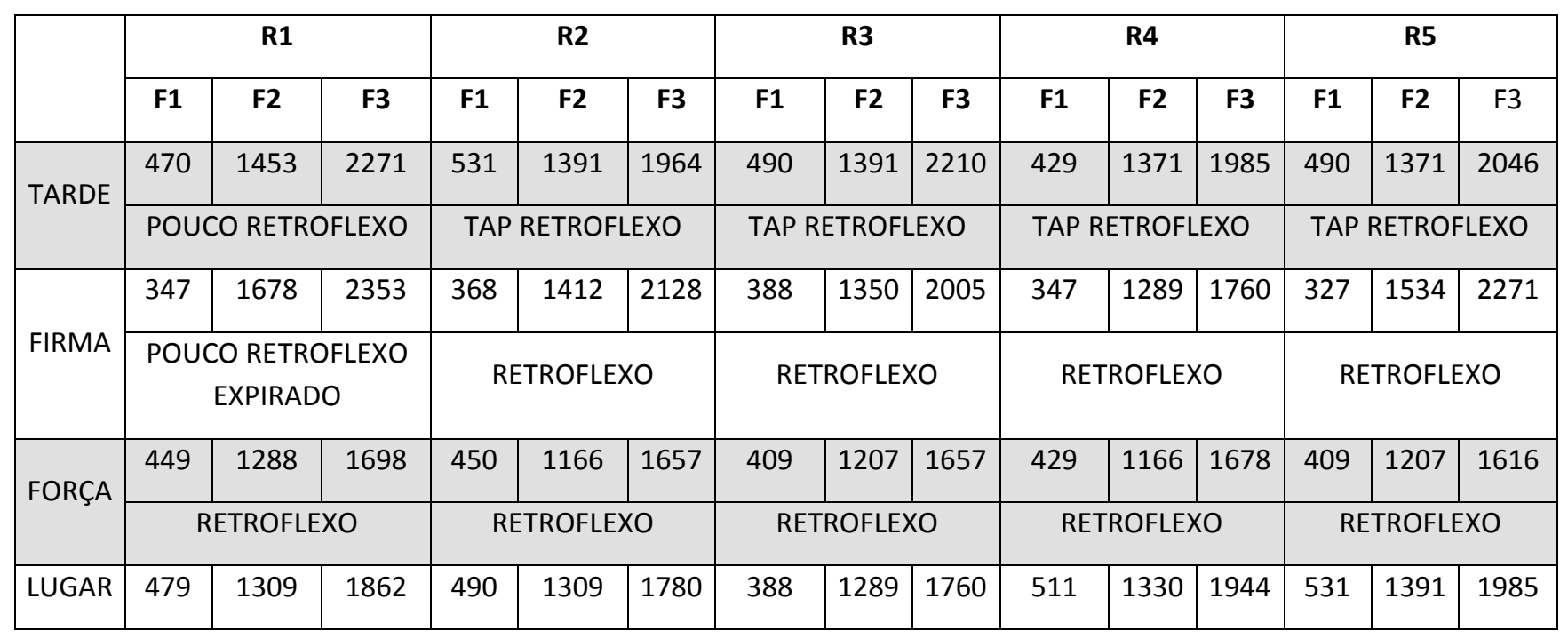




\begin{tabular}{|c|c|c|c|c|c|c|c|c|c|c|c|c|c|c|c|}
\hline & \multicolumn{3}{|c|}{ RETROFLEXO } & \multicolumn{3}{|c|}{ RETROFLEXO } & \multicolumn{3}{|c|}{ RETROFLEXO } & \multicolumn{3}{|c|}{ TAP RETROFLEXO } & \multicolumn{3}{|c|}{ RETROFLEXO } \\
\hline \multirow[b]{2}{*}{ VIZIR } & 328 & 1575 & 2046 & 348 & 1350 & 1780 & 347 & 1555 & 2046 & 359 & 1534 & 1985 & 347 & 1453 & 1882 \\
\hline & \multicolumn{3}{|c|}{ APROX. ALV. } & \multicolumn{3}{|c|}{ RETROFLEXO } & \multicolumn{3}{|c|}{$\begin{array}{c}\text { RETROFLEXO } \\
\text { EXPIRADO }\end{array}$} & \multicolumn{3}{|c|}{ RETROFLEXO } & \multicolumn{3}{|c|}{ RETROFLEXO } \\
\hline \multirow{2}{*}{ CALOR } & 429 & 1227 & 1760 & 429 & 1146 & 1616 & 429 & 1125 & 1739 & 409 & 1166 & 1575 & 429 & 1146 & 1698 \\
\hline & \multicolumn{3}{|c|}{ RETROFLEXO } & \multicolumn{3}{|c|}{ RETROFLEXO } & \multicolumn{3}{|c|}{ RETROFLEXO } & \multicolumn{3}{|c|}{ RETROFLEXO } & \multicolumn{3}{|c|}{ RETROFLEXO } \\
\hline
\end{tabular}

\section{INFORMANTE Y}

\begin{tabular}{|c|c|c|c|c|c|c|c|c|c|c|c|c|c|c|c|}
\hline & \multicolumn{3}{|c|}{ R1 } & \multicolumn{3}{|c|}{ R2 } & \multicolumn{3}{|c|}{ R3 } & \multicolumn{3}{|c|}{ R4 } & \multicolumn{3}{|c|}{ R5 } \\
\hline & F1 & F2 & F3 & F1 & F2 & F3 & F1 & F2 & F3 & F1 & F2 & F3 & F1 & F2 & F3 \\
\hline \multirow{2}{*}{ TARDE } & 531 & 1780 & 2455 & 491 & 1800 & 2435 & 511 & 1739 & 2414 & 490 & 1903 & 2619 & 511 & 1862 & 2394 \\
\hline & \multicolumn{3}{|c|}{ RETROFLEXO } & \multicolumn{3}{|c|}{ RETROFLEXO } & \multicolumn{3}{|c|}{ RETROFLEXO } & \multicolumn{3}{|c|}{ RETROFLEXO } & \multicolumn{3}{|c|}{ RETROFLEXO } \\
\hline \multirow{2}{*}{ FIRMA } & 429 & 1944 & 2721 & 441 & 1923 & 2803 & 409 & 1985 & 2783 & 429 & 1923 & 2742 & 430 & 1964 & 2701 \\
\hline & \multicolumn{3}{|c|}{ TAP } & \multicolumn{3}{|c|}{ TAP } & \multicolumn{3}{|c|}{ TAP FRACO } & \multicolumn{3}{|c|}{ TAP } & \multicolumn{3}{|c|}{ TAP } \\
\hline \multirow[b]{2}{*}{ FORÇA } & 430 & 1371 & 1985 & 490 & 1330 & 2210 & 488 & 1350 & 2026 & 409 & 1350 & 2066 & 511 & 1432 & 2333 \\
\hline & \multicolumn{3}{|c|}{ RETROFLEXO } & \multicolumn{3}{|c|}{ RETROFLEXO } & \multicolumn{3}{|c|}{ RETROFLEXO } & \multicolumn{3}{|c|}{ RETROFLEXO } & \multicolumn{3}{|c|}{$\begin{array}{c}\text { POUCO } \\
\text { RETROFLEXO }\end{array}$} \\
\hline \multirow[b]{2}{*}{ LUGAR } & 511 & 1637 & 2373 & 593 & 1575 & 2271 & 552 & 1575 & 2312 & 511 & 1514 & 2128 & 511 & 1555 & 2251 \\
\hline & \multicolumn{3}{|c|}{ POUCO RETROFLEXO } & \multicolumn{3}{|c|}{ POUCO RETROFLEXO } & \multicolumn{3}{|c|}{ POUCO RETROFLEXO } & \multicolumn{3}{|c|}{ RETROFLEXO } & \multicolumn{3}{|c|}{$\begin{array}{c}\text { POUCO } \\
\text { RETROFLEXO }\end{array}$} \\
\hline \multirow[b]{2}{*}{ VIZIR } & 469 & 1841 & 2578 & 388 & 1985 & 2619 & 388 & 1964 & 2619 & 409 & 1814 & 2414 & 409 & 2005 & 2660 \\
\hline & \multicolumn{3}{|c|}{ TAP FRACO } & \multicolumn{3}{|c|}{ TAP } & \multicolumn{3}{|c|}{$\begin{array}{c}\text { QUASE } \\
\text { APAGAMENTO }\end{array}$} & \multicolumn{3}{|c|}{$\begin{array}{c}\text { QUASE } \\
\text { APAGAMENTO }\end{array}$} & & $\begin{array}{l}\text { QUASE } \\
\text { GAME }\end{array}$ & VTO \\
\hline & 368 & 1105 & 2210 & 430 & 1248 & 2148 & 368 & 1289 & 1903 & 409 & 1330 & 2005 & 419 & 1227 & 1964 \\
\hline & & ROFLE & & & ROFLE & & & ROFLE & & & ROFLEX & & & TROFL & \\
\hline
\end{tabular}

\section{INFORMANTE Z}

\begin{tabular}{|c|c|c|c|c|c|c|c|c|c|c|c|c|c|c|c|}
\hline & \multicolumn{3}{|c|}{ R1 } & \multicolumn{3}{|c|}{$\mathbf{R 2}$} & \multicolumn{3}{|c|}{ R3 } & \multicolumn{3}{|c|}{ R4 } & \multicolumn{3}{|c|}{ R5 } \\
\hline & F1 & F2 & F3 & F1 & F2 & F3 & F1 & F2 & F3 & F1 & F2 & F3 & F1 & F2 & F3 \\
\hline \multirow{2}{*}{ TARDE } & 491 & 1719 & 2333 & 449 & 1821 & 2312 & 470 & 1800 & 2373 & 511 & 1787 & 2066 & 429 & 1821 & 2414 \\
\hline & \multicolumn{3}{|c|}{ RETROFLEXO } & \multicolumn{3}{|c|}{ RETROFLEXO } & \multicolumn{3}{|c|}{ POUCO RETROFLEXO } & \multicolumn{3}{|c|}{ RETROFLEXO } & \multicolumn{3}{|c|}{ RETROFLEXO } \\
\hline \multirow{2}{*}{ FIRMA } & 449 & 1964 & 2926 & 430 & 1800 & 2905 & 471 & 1780 & 2946 & 450 & 1985 & 3008 & 429 & 2046 & 2967 \\
\hline & \multicolumn{3}{|c|}{ APROX. ALV. } & \multicolumn{3}{|c|}{ APROX. ALV. } & \multicolumn{3}{|c|}{ APROX. ALV. } & \multicolumn{3}{|c|}{ APROX. ALV. } & \multicolumn{3}{|c|}{ APROX. ALV. } \\
\hline FORÇA & 450 & 1534 & 2373 & 491 & 1555 & 2333 & 470 & 1534 & 2353 & 450 & 1544 & 2373 & 470 & 1555 & 2353 \\
\hline
\end{tabular}


http://dx.doi.org/10.5007/1984-8420.2014v15n1p136

\begin{tabular}{|c|c|c|c|c|c|c|c|c|c|c|c|c|c|c|c|}
\hline & \multicolumn{3}{|c|}{ RETROFLEXO } & \multicolumn{3}{|c|}{ RETROFLEXO } & \multicolumn{3}{|c|}{ RETROFLEXO } & \multicolumn{3}{|c|}{ RETROFLEXO } & \multicolumn{3}{|c|}{ RETROFLEXO } \\
\hline \multirow{2}{*}{ LUGAR } & \multirow{2}{*}{\multicolumn{3}{|c|}{ APAGAMENTO }} & \multirow{2}{*}{\multicolumn{3}{|c|}{ APAGAMENTO }} & 552 & 1678 & 2558 & 552 & 1739 & 2455 & 511 & 1760 & 2537 \\
\hline & & & & & & & \multicolumn{3}{|c|}{ TAP EXPIRADO } & \multicolumn{3}{|c|}{ POUCA RETRFLEXO } & \multicolumn{3}{|c|}{ TAP EXPIRADO } \\
\hline \multirow{2}{*}{ VIZIR } & 389 & 2026 & 2803 & 409 & 1964 & 2823 & 450 & 1985 & 2885 & 470 & 1985 & 2926 & 409 & 2005 & 2905 \\
\hline & \multicolumn{3}{|c|}{ APROX. ALV. } & \multicolumn{3}{|c|}{ APROX. ALV. } & \multicolumn{3}{|c|}{ APROX. ALV. } & \multicolumn{3}{|c|}{ APROX. ALV. } & \multicolumn{3}{|c|}{ APROX. ALV. } \\
\hline \multirow{2}{*}{ CALOR } & 488 & 1494 & 2639 & 511 & 1534 & 2742 & 471 & 1494 & 2783 & 429 & 1514 & 2824 & 450 & 1504 & 2987 \\
\hline & \multicolumn{3}{|c|}{$\frac{1}{1}$} & \multicolumn{3}{|c|}{ TAP EXPIRADO } & \multicolumn{3}{|c|}{$\frac{1}{\text { TAP EXPIRADO }}$} & \multicolumn{3}{|c|}{$\frac{1}{\text { TAP EXPIRADO }}$} & \multicolumn{3}{|c|}{ TAP EXPIRADO } \\
\hline
\end{tabular}

